

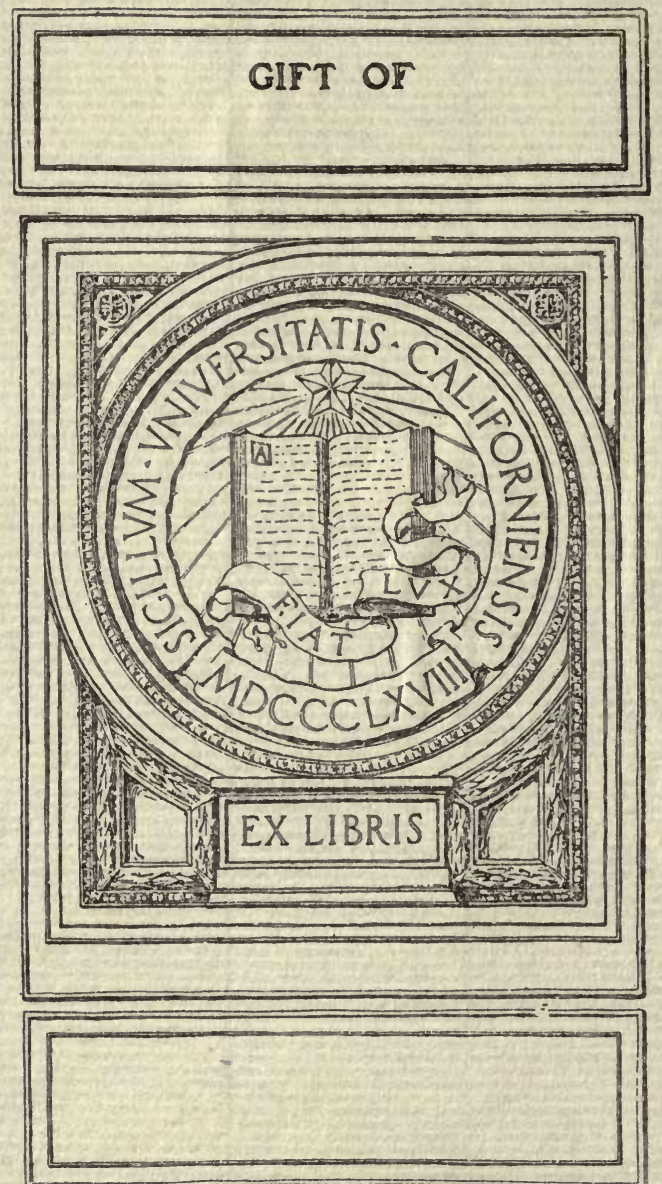


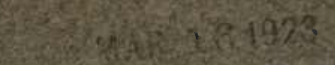

$\vdots \vdots \vdots \because, \quad \therefore$

$\therefore \quad \therefore \quad \therefore \because \div 3 \div \therefore$

\section{DEPARTMENT OF AGRICULTLRE}

\section{FOREST PRODUCTS LABORATORY}

\section{REPORT PREPARED FOR}

THE COMMISSION OF THE UNITED STATES OF AMERICA TO THE BRAZIL CENTENNIAL EXPOSITION

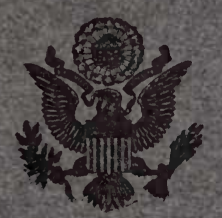

For Distribution at the Brazil Centennial Exposition 1922-1923 


\section{$\because \because \because \quad \vdots \because \vdots \because \vdots \vdots$ \\ $\therefore \because \vdots \because \because \because \because \because \vdots \quad$ : $\because \because \vdots$}

\section{-}

.

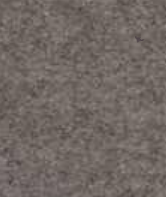

2.

at 


\title{
DEPARTMENT OF AGRICULTURE
}

\section{FOREST PRODUCTS LABORATORY}

\author{
$\nabla$
}

Supplementing Exhibit

of the

UNITED STATES FOREST SERVICE

at the

BRAZIL CENTENNIAL EXPOSITION

Rio de Janeiro, Brazil

1922-1923

By

HERBERT A. SMITH

United States Forest Service 


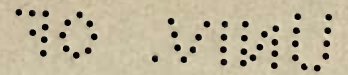

¿@
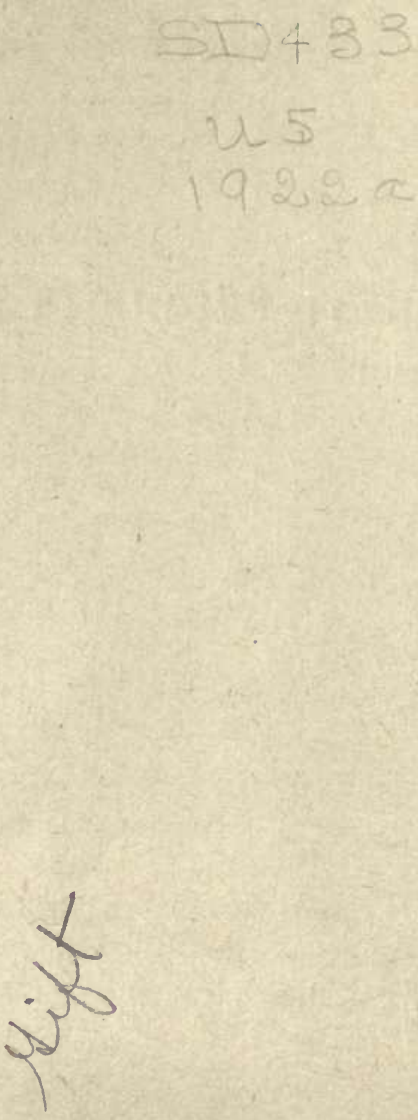


\section{FOREST PRODUCTS LABORATORY.}

\section{A BRIFF ACCOUNT OF ITS WORK AND AIMS.}

The Forest Products Laboratory is a unit in the Branch of Research of the Forest Service, United States Department of Agriculture. It is ocated at Madison, Wis., and is conducted in cooperation with the University of Wisconsin.

For several years after its establishment, in I9ro, it was the only nstitution of its kind in the world conducted with the object of turning he searchlight of research upon wood and its uses and making the information thus obtained available to the public.

\section{PUBLIC SERVICE.}

\section{SCOPE OF ACTIVITIES.}

The purpose of the Forest Service in the administration of the Forest Products Laboratory is to conserve American forests by developing the nost economical methods of converting standing trees into finished prodicts. The purpose is also to make the growing of timber more profitale by increasing the possibilities in the utilization of both used and inused species. The Laboratory seeks to develop not only new and more fficient processes, but to find ways of utilizing material which would therwise be wasted, to find new uses for old materials and new materials or old uses. In a word, the aim is to render practical assistance to the manufacturers and users of wood and wood products and at the same time o promote forest conservation and the practice of forestry.

Every American industry and class of consumers which uses or grows rood or any other product of the forest may thus be a beneficiary of the vork done at the Laboratory. Every such industry, class of consumers, and timber producers is a potential cooperator in the Laboratory's work. ts objects are sought not only through experiments conducted at the Laboratory but also through the detail of its men to work on important problems in the mills and factories and the receiving of representatives of he industries at the Laboratory to work beside its scientific men.

\section{VALUE OF WORK.}

The value of this work has already made itself apparent. The redicion of waste, the better utilization of the products of the tree, the utiliza$\therefore$ i of species hitherto wasted, the added life given to many kinds of 
wood products by more efficient preservative methods, the reduction 0 : the degrade in lumber by efficient dry-kiln methods, and many other savings are an enormous help in conserving the timber supply.

\section{RESULTS AVAILABLE TO PUBLIC.}

The value of the Forest Products Laboratory to any particular wood 11sing industry or class of consumers depends to a very large extent upor the use which that industry makes of it. It is a Government institutior supported mainly by Government appropriations, and its advice anc suggestions are to be had for the asking. It presents an opportunity for every manufacturer, user, and timber grower to supplement the informa tion obtained by experience and hard knocks with technical data obtainec through scientific research.

\section{PLACE IN FOREST CONSERVATION.}

The work of the Laboratory is of direct value to those engaged in timber production. To a very large extent the kinds and sizes of forest

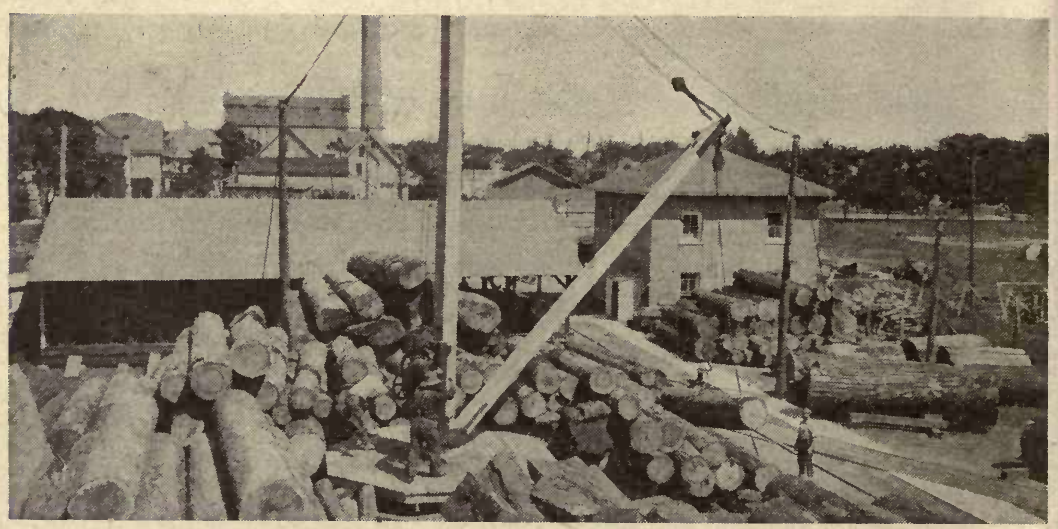

trees which should be grown and the purposes for which they should be produced are dependent on the mechanical, physical, and chemical properties of their wood and the uses to which they can most profitably be put In the administration of the National Forests and of privately owned timberlands, in the activities of the State forestry departments, and in the instruction given by the forest schools the results secured by the Laboratory play an important part. By reducing the present waste of three-fourths of every tree cut and making possible the most efficient utilization of the one-fourth used they are contributing in a very essential way to forest conservation and to profitable timber production. Through its forest products research the Forest Service supplements its efforts to bring about the growing of timber by information which should make possible the most complete and effective utilization. 


\section{ORGANIZATION FOR RESEARCH.}

\section{COORDINATED RESEARCH.}

Research is increasingly effective in proportion as it is carefully planned ind executed. At the beginning of each year a program covering as nearly is practicable the work of the Laboratory for the ensuing year is conidered and approved. Individual initiative and responsibility are given he widest possible opportunity, but at the same time the work of different nen is so coordinated by an interchange of ideas among the different ections, and other means, that duplication is avoided and cumulative esults are obtained.

\section{ORGANIZATION OF THE LABORATORY.}

The Laboratory is in charge of a director, an assistant director, and a ; taff comprised of the heads of the different research and administrative ;ections. In each section are men of broad general experience with wood

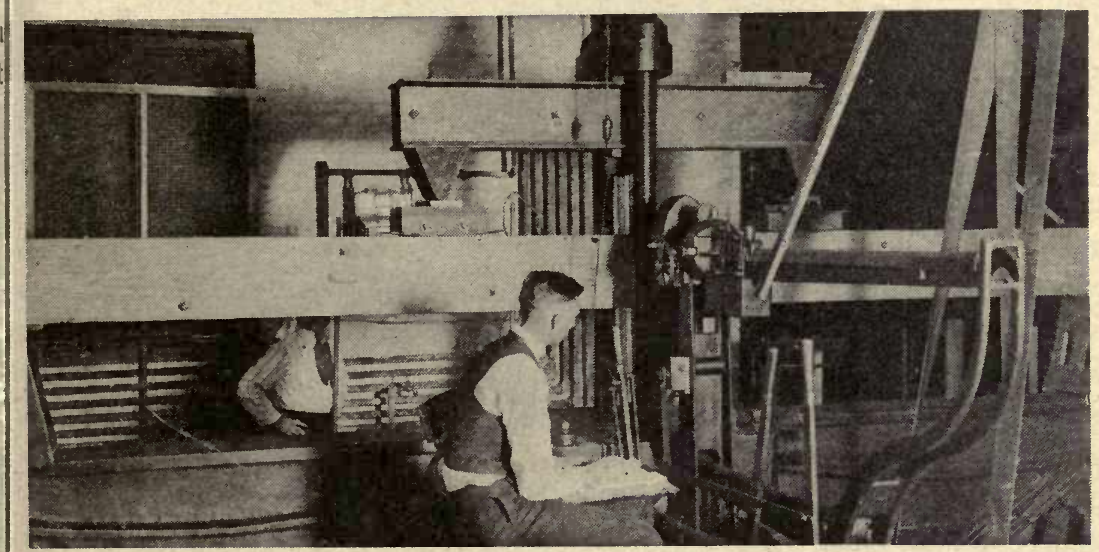

and knowledge of its characteristics, and other specialists in various wood uses, who devote their whole time to the study of special problems. These men are recruited, in accordance with the regulations of the Civil Service Commission, from the professions of engineering, chemistry, forestry, and pathology.

The work of the Laboratory is distributed among the following technical sections:

Timber mechanics. - Strength of wood and manufactured articles.

Timber physics.-Experimental and applied kiln drying, physical properties, identification, and structure of wood.

Wood preservation.-Wood treatments, glues, and laminated construction.

Pulp and paper.-Manufacturing methods and suitability of various woods for pulp, paper, and special products.

Derived products. - Chemical properties and uses of wood and chemical wood products, such as turpentine, alcohol, acetic acid, etc. 
Industrial investigations.-Methods and practices in the lumber and other wood-using industries, grades, specifications, and mill scale studies.

Pathology (in cooperation with the Bureau of Plant Industry).-Decay of timber, molds, stains in manufactured wood products, and antiseptic properties of wood preservatives.

\section{TIMBER MECHANICS.}

Knowledge of the mechanical properties of woods and wood products is essential for their intelligent and economic use, whether in the factory, on the farm, in the home, on the railroad, in the mine, or in the air. Thus development of the airplane and progress in many other lines depend in a large measure on accurate information as to the strength, toughness, elasticity, and other mechanical properties which deternine the suitability of different woods for various purposes. To supply this information, over 500,000 mechanical tests have been made, as nearly as possible under standardized conditions, so that the tests made for a single purpose will have the broadest application and will serve for many uses.

STRENGTH OF VARIOUS SPECIES.

Data from tests of small clear specimens are now available in 150 species of woods grown in the United States, as well as data, in some cases meager, in some cases fairly complete, on about 60 species, principally from South America and the Philippines. These data are of particular value in comparing the properties of the different species, in finding substitutes for the scarcer and higher-priced woods, in selecting species for particular uses, and in establishing correct working stresses. The results of these tests on small clear specimens also furnish definite information on the variability of wood and show the necessity of grading timber for all uses where strength is of prime importance.

A large number of tests have also been made on full-sized timbers, such as bridge stringers, factory-building timbers, and car sills. These tests have demonstrated the influence of defects, such as knots, shakes, and checks, on strength; and, altogether with the results of tests on small clear specimens, furnish the basis for the establishment of grading rules and correct working stresses for structural timbers.

Tests have been made on plywood to determine the strength of different combinations of species, the effect of increasing the number of plies, and the effect of varying the ratio of core thickness to total panel thickness. Some data are also available on factors affecting warping, on strength of fastenings for plywood, on the efficiency of joints in plywood, and on the strength in tension. Information on such points as these places the Laboratory in a position to assist users and manufacturers of plywood and veneer products in solving problems encountered in developing new uses for these products in the various industries. 


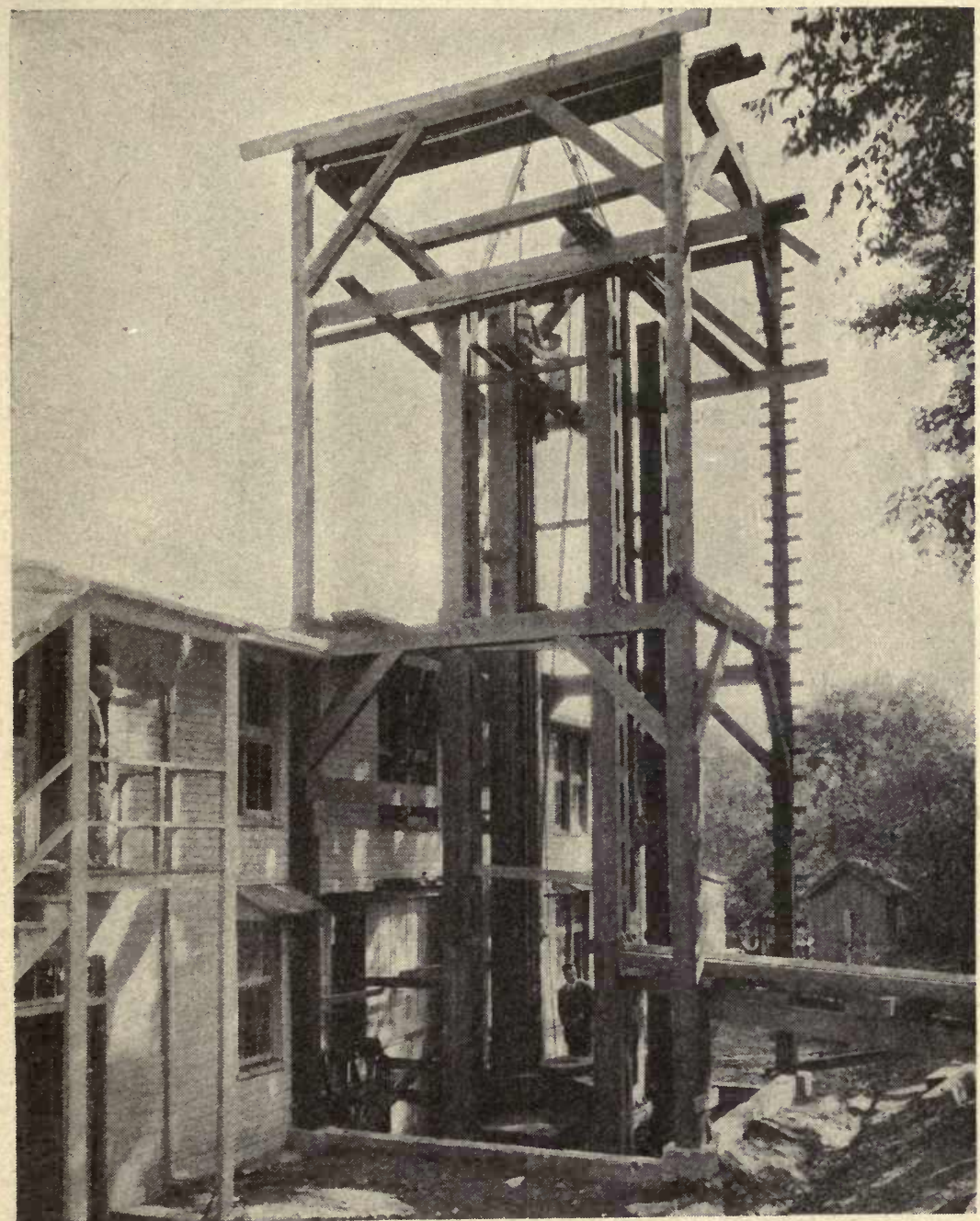

The largest of the testing machines, shown here in the process of erection, is capable of exerting a force of a million pounds and can test to destruction wooden columns 30 feet long and a foot square. 


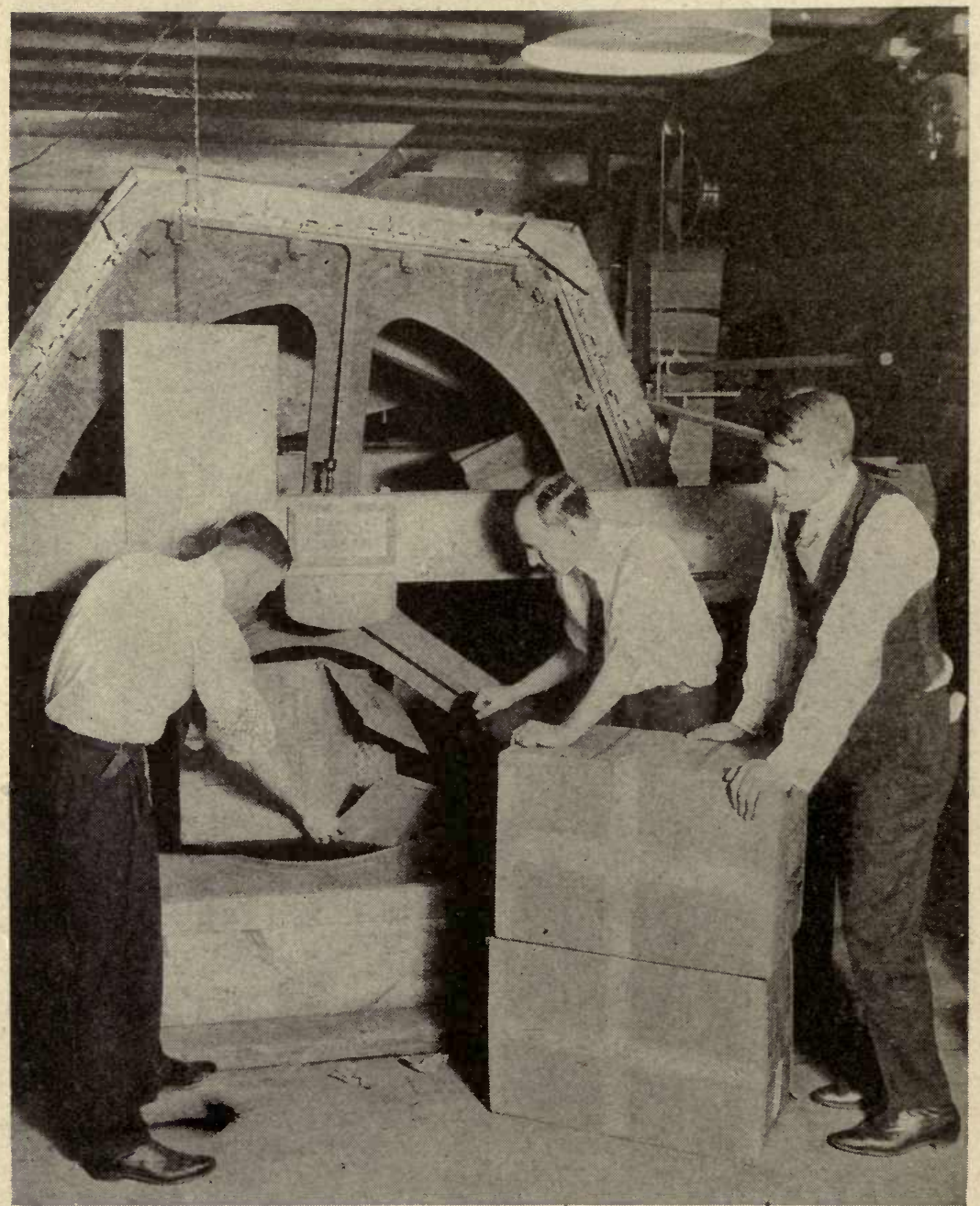

The drum testing machine, developed by the Laboratory to simulate the hazards of transportation, has become standard for shippers, packers, and manufacturers. The boxes shown are packed with electriclight bulbs. Four thousand dollars' worth of bulbs were furnished by the electric companies concerned for this series of tests to develop a better container. 


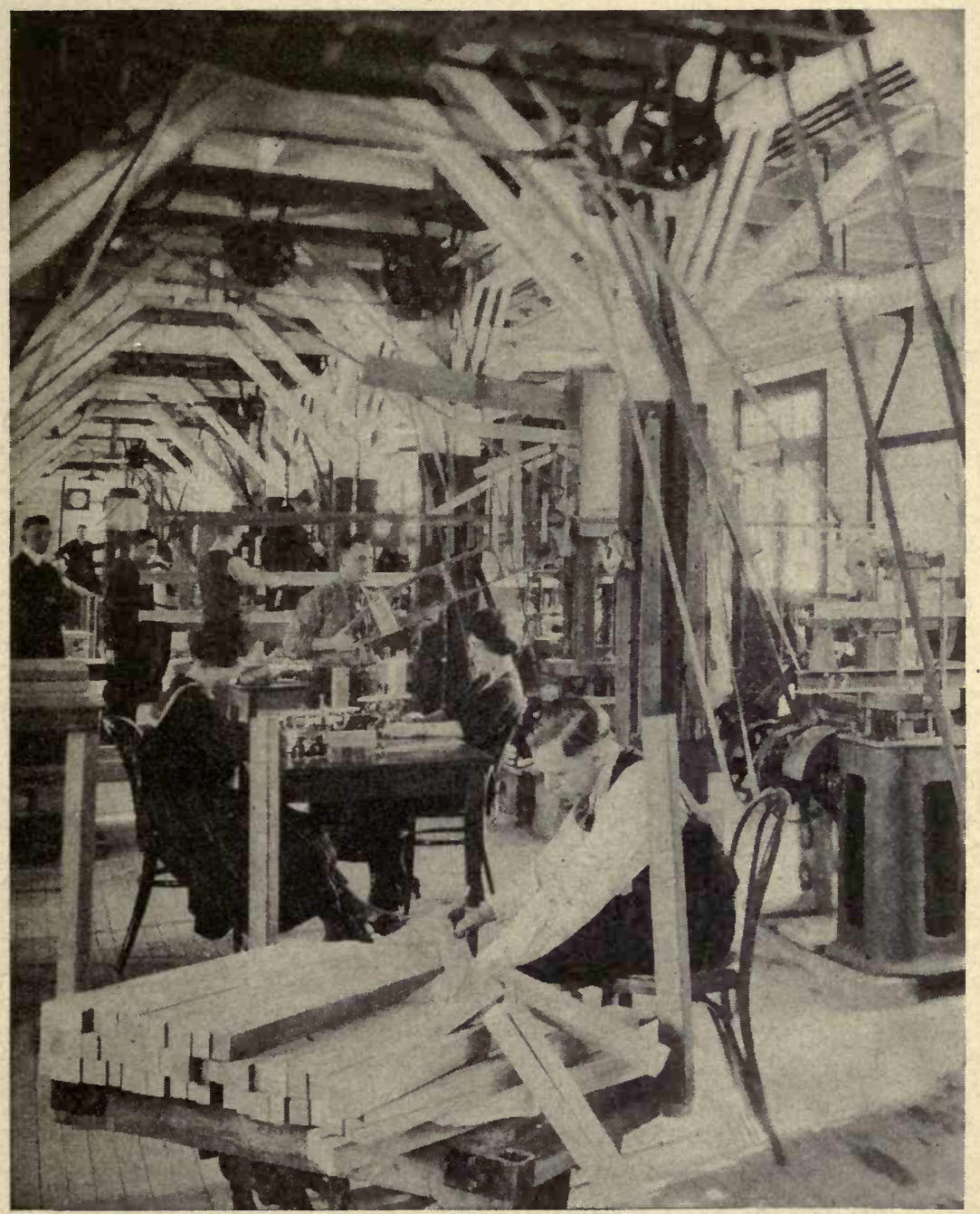

Some of the strength-testing machines, such as the one at the right, are employed chiefly in determining the strength properties of native woods, using small, clear specimens like those on the truck. Other machines are rigged up to test wooden parts. A newly designed airplane wing rib is just being placed in the machine second in line.

$11958-22-2$ 


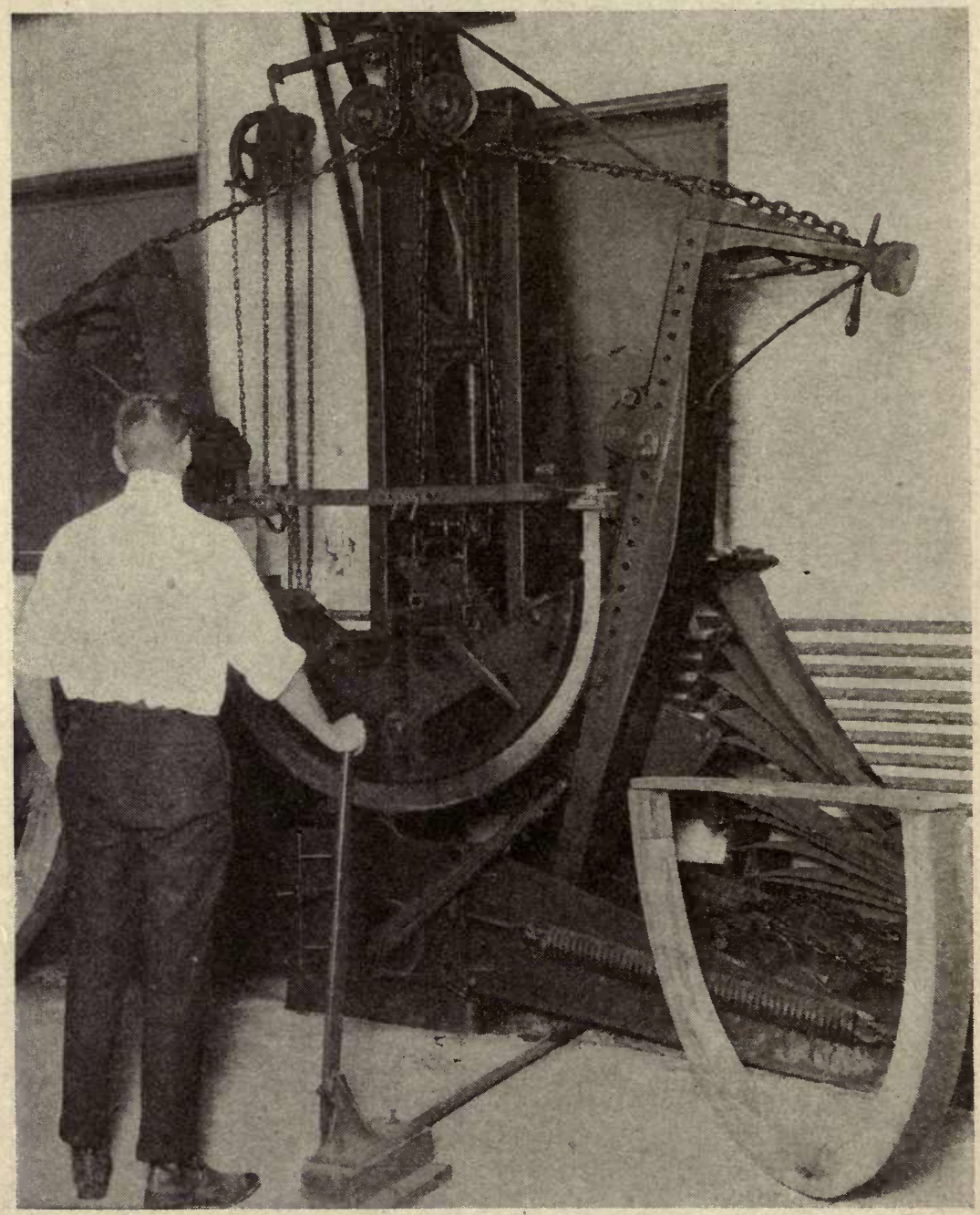

Furniture and vehicle factories are concerned in the research of the Laboratory to reduce losses in the steam bending of stock. To bend a heavy wheel rim, such as is shown, without fracture, requires a careful preliminary conditioning treatment. 
TESTS ON SHIPPING CONTAINERS.

The results of tests on containers are of particular interest to all shippers, box manufacturers, and transportation companies, and are also of great importance to the public in general. The damage due to the failure of containers in transportation amounts annually to many millions of dollars. There are, in addition, large losses due to improper packing. All of the work done at the Laboratory in this field tends directly to reduce these enormous losses, which are ultimately paid by the consumer. A considerable amount of fundamental data relating to the construction of boxes and crates has been obtained which finds direct application in the redesign of faulty containers and in the development of new containers. It is frequently possible to redesign a container so as to reduce the amount of material required, to save shipping and warehouse space, and at the same time to obtain greater serviceability.

\section{DRUM TESTS.}

Revolving-drum tests, together with drop and compression tests of boxes loaded with either actual or dummy contents, have been used in determining the characteristic weakness of the various types of containers. The Forest Products Laboratory standard drum is 14 feet in diameter and can accommodate packages up to 1,000 pounds in weight. It is fitted with hazards so arranged that the container under test follows a regular cycle of drops which simulate those received in actual transportation. The field for this work is very large, and much remains to be done in order to develop fundamental relations between the weight and the nature of the commodity, the type of box to be used, and the thickness of the bottom, side, and end boards.

\section{TESTS OF MANUFAC'TURED ARTICLES.}

Tests on vehicle and implement parts, airplane parts, doors, and other articles manufactured of wood are made primarily to demonstrate the fitness of substitute species, to develop or improve designs, and to obtain more economical and efficient use of wood. The limitations and possibilities of splices and laminated construction are being studied with a view to conserving lumber through the increased use of small pieces and low grades. This should make possible the use of smaller trees, which can be grown in comparatively short periods, in short, the character of material on which the country will have to depend very largely in the future and which can be grown most profitably. 


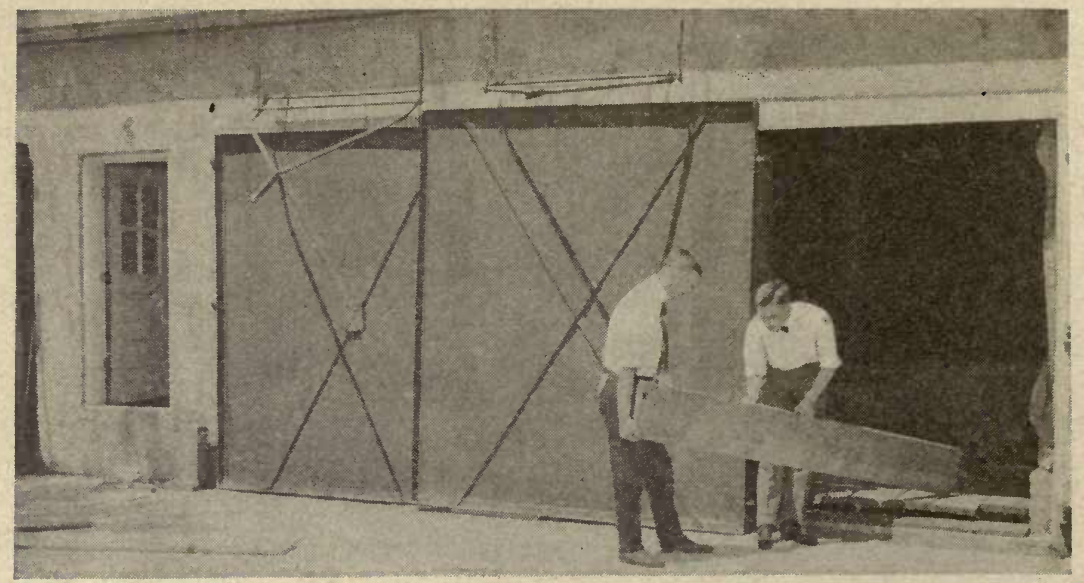

TIMBER PHYSICS.

KILN DRYING.

A knowledge of the physical properties of wood is of importance to almost every industry using wood and is essential in kiln drying, impregnation with preservatives, distillation, and other treatments. These physical properties include density, shrinkage, transfusion of moisture, hygroscopicity, specific heat, heat conductivity, heat of absorption of water in wood, and permeability of wood by liquids and gases.

It is often necessary for financial reasons to reduce the time required properly to season wood by open-air drying. Moreover, for-many purposes it is desirable to dry the wood more thoroughly than is possible in the open air and to employ conditions which will reduce its hygroscopicity, or tendency to shrink or swell. For these reasons dry kilns are almost universally employed for high-grade lumber, and frequently even for the poorer grades. In the drying of hardwoods it is estimated that about Io per cent of the material dried is either ruined or lowered in grade. Much of this loss could be avoided by proper methods and kilns, and the present results might be greatly improved in other respects.

\section{ESTABLISHING SCIENTIFIC PRINCIPLES.}

The Forest Products Laboratory bases all its kiln-drying practice on fundamental studies to determine the principles underlying the transfusion of moisture through wood, the effect of changes in atmospheric conditions upon the rate of transfusion, the effect of various methods of drying and of various drying treatments upon the properties of the wood being dried, and similar studies.

\section{DRYING SCHEDULES.}

A comprehensive series of experiments is being conducted to determine the proper "drying schedules" for all important commercial woods. These drying schedules will show the proper conditions of temperature 


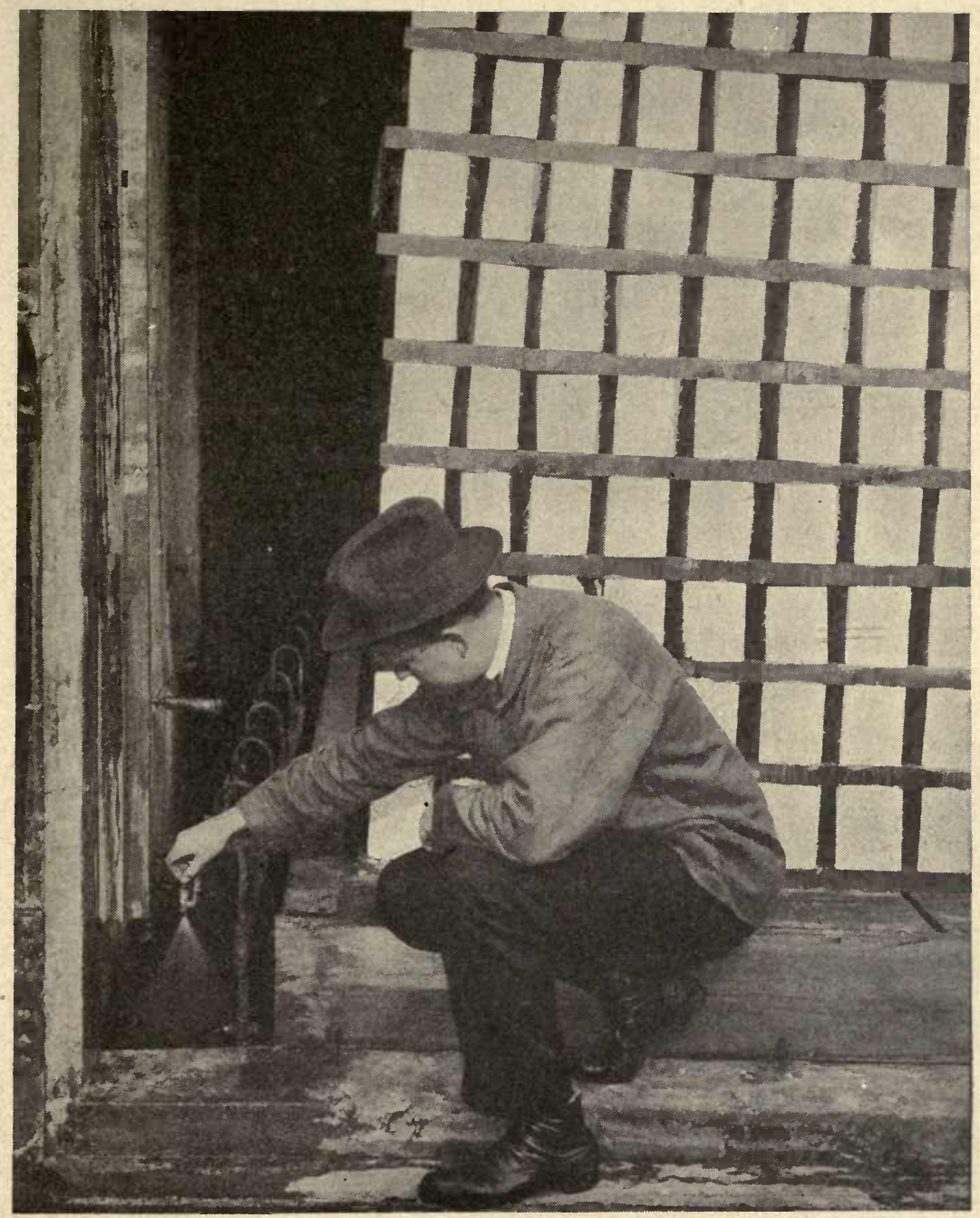

The distinctive feature of the Forest Service water-spray kiln is the control of the humidity in the kiln and, consequently, the drying rate of the lumber, by conditioning the air with sprays of water whose temperature is carefully regulated. The experimental kiln shown is drying oak bolster stock, which appears white because of the end dip used to reduce checking. 
and humidity to obtain best results in drying, and they will cover the entire range from an absolutely green condition to absolute dryness. A number of drying schedules have already been published. This class of work has direct application throughout the wood-using industries.

STEAM BENDING.

The proper steam bending of heavy wooden parts, such as artillery wheel rims, presents a number of problems on which the Laboratory has done a limited amount of work and on which it plans to do much more in the near future. The proper moisture condition of the stock, the length and temperature of steaming or other preliminary treatment, and the mechanical details of the actual bending must all be worked out before present high losses in this process can be overcome.

\section{IDENTIFICATION.}

The accurate identification of woods is important not only in the investigative work of the Laboratory, where it is essential that the kind of wood under test be definitely known, but to wood users generally. There is a steadily increasing demand in the various industries for service of this character, and several thousand specimens of wood are annually identified for outside concerns. Microscopic slides and photomicrographs made from the slides have been prepared for practically all American woods of importance and are available for study. Authentic specimens of most species aré also available.

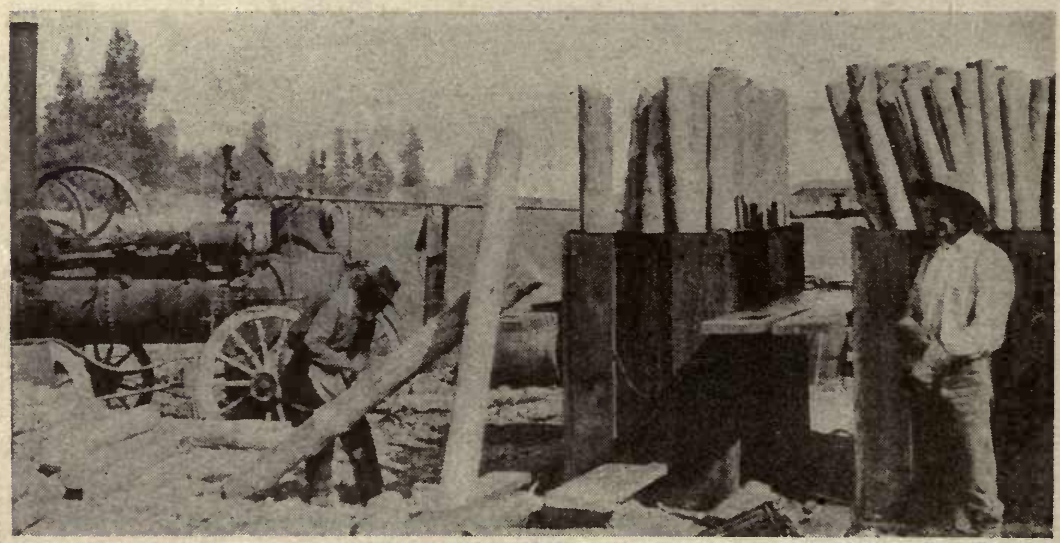

\section{WOOD PRESERVATION.}

\section{PRESERVATIVES.}

The amount of wood in the form of railroad ties, mine timbers, posts, poles, and other products which is destroyed each year by decay is estimated at from one-half to three-quarters of a billion cubic feet. It is therefore important to devise methods of treating wood with preservatives that will reduce this waste to a minimum. 


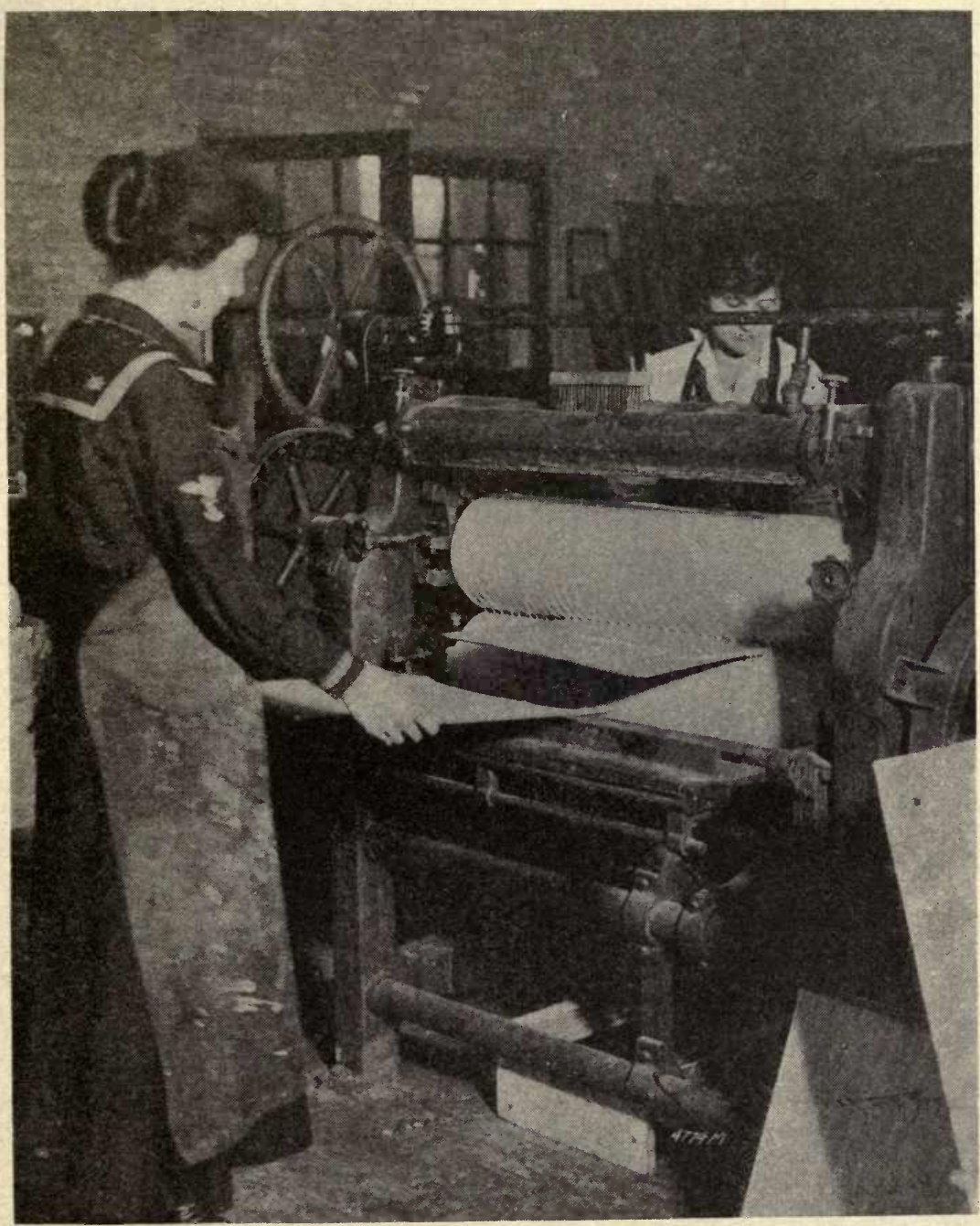

In the manufacture of water-resistant plywood with casein glue, the glue is applied cold to the veneer sheets by means of a mechanical glue spreader. The sheets are then placed one on top of another in a press. 


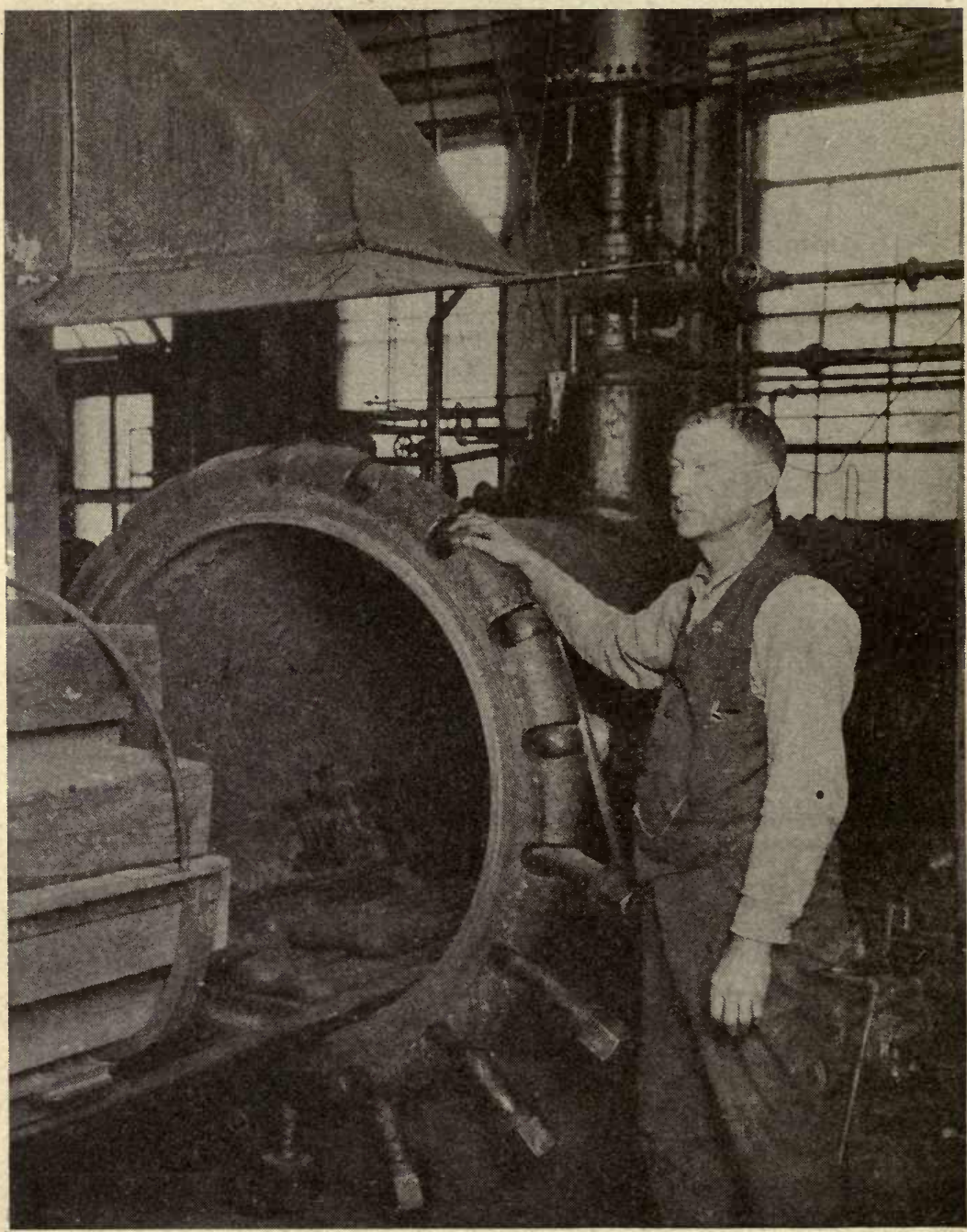

The life of railroad ties treated with preservatives is often double that of untreated ties. The illustration shows some red-oak ties about to undergo an experimental treatment with creosote in the pressure cylinder. Afterwards they will be placed in actual service in one of the test tracks maintained by the railroads in cooperation with the Laboratory 
In treating operations, the cost of the preservative, such as creosote, zinc chloride, or sodium fluoride, amounts to a high percentage of the total cost. Furthermore, the ultimate success of any treatment is largely dependent upon the preservative used. Much information has already been obtained concerning the preservatives now in common use, but there is need for a great deal of further study with the object of developing new preservatives which will either be cheaper or more effective than present preservatives or will have properties fitting them for wider use or for special purposes. The value of a preservative is not considered established until it has had a thorough trial under actual service conditions.

\section{GLUES FOR PLYWOOD.}

In connection with the manufacture of plywood, studies have been made of animal glues, such as those made from hide, bone, and other products; and standard methods of testing have been developed. A suitable "standard glue" for aircraft work and high-class joint work in general has been selected and samples made available to manufacturers and users. This is the glue adopted as standard by Army and Navy aircraft bureaus.

The development of water-resistant glues of several types, including casein glues and blood-albumin glues, has been progressing for several years, and a number of high-grade glues have been perfected. Tests and experiments are being carried forward to improve these glues still more, especially in their resistance to moisture.

\section{LAMINATED AND BUILT-UP PARTS.}

One of the lines of investigation to be taken up recently is the determination of possibilities and best practices in the design and construction of structural members built up of small pieces glued together. These investigations were carried out intensively on aircraft parts, such as wing beams and struts, when the success of the aircraft program was threatened by a sudden shortage of suitable material in the required sizes. The knowledge gained is being applied to extensive investigations of the use of laminated and built-up construction in the various woodusing industries for the manufacture of such articles as shoe lasts, hat blocks, bowling pins, wagon bolsters, and wheel hubs.

The Laboratory has done considerable work on the moisture resistance of various wood coatings, and a very efficient aluminum leaf coating has been developed which affords protection against moisture over long periods of storage. Tests are now in progress on the durability of these coatings. Other work on wood finishes is contemplated. 


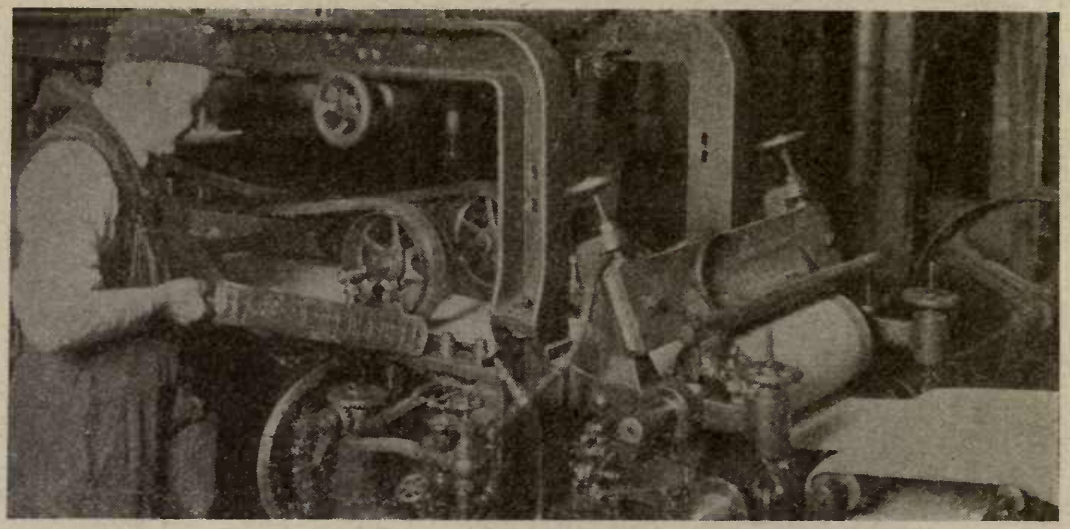

PULP AND PAPER.

The constantly decreasing supply of suitable pulp woods and the ever-increasing demand for paper of all kinds, especially newsprint paper, have combined to produce so serious a situation that investigations into methods of conserving the supply of pulp wood and increasing the production of paper are of paramount importance.

\section{PROCESSES OF PULP AND PAPER MAKING.}

The Laboratory is conducting experiments on methods of making wood pulp and has already developed several important improvements in the standard chemical processes.

A very important field of research lies in determining the suitability of various little-used woods as substitutes for those most commonly used. Practically all available species which give promise of suitability are being investigated, and proper methods of grinding or cooking of most of the important ones have already been worked out.

\section{UTILIZATION OF WASTE.}

Studies of waste utilization in the pulp and paper industry have been in progress for some time along a number of distinct lines. For example, feasible methods of turning sawmill waste, such as slabs, into pulp have been determined. The use of a certain percentage of spent tanbark in the manufacture of roofing felts has been investigated and a method developed whereby what was formerly a waste of the tanning industry is now in profitable commercial use. The possibility of using hemlockbark waste for tannin has also been demonstrated.

A commercially feasible method of recovering both the paraffin and the fiber from waxed paper trimmings has been developed. Studies of the wastes incident to the pulp industries, such as sulphite waste liquors and soda liquors, in which are now carried off approximately half of the wood that enters into the digesters, are to be undertaken intensively as 


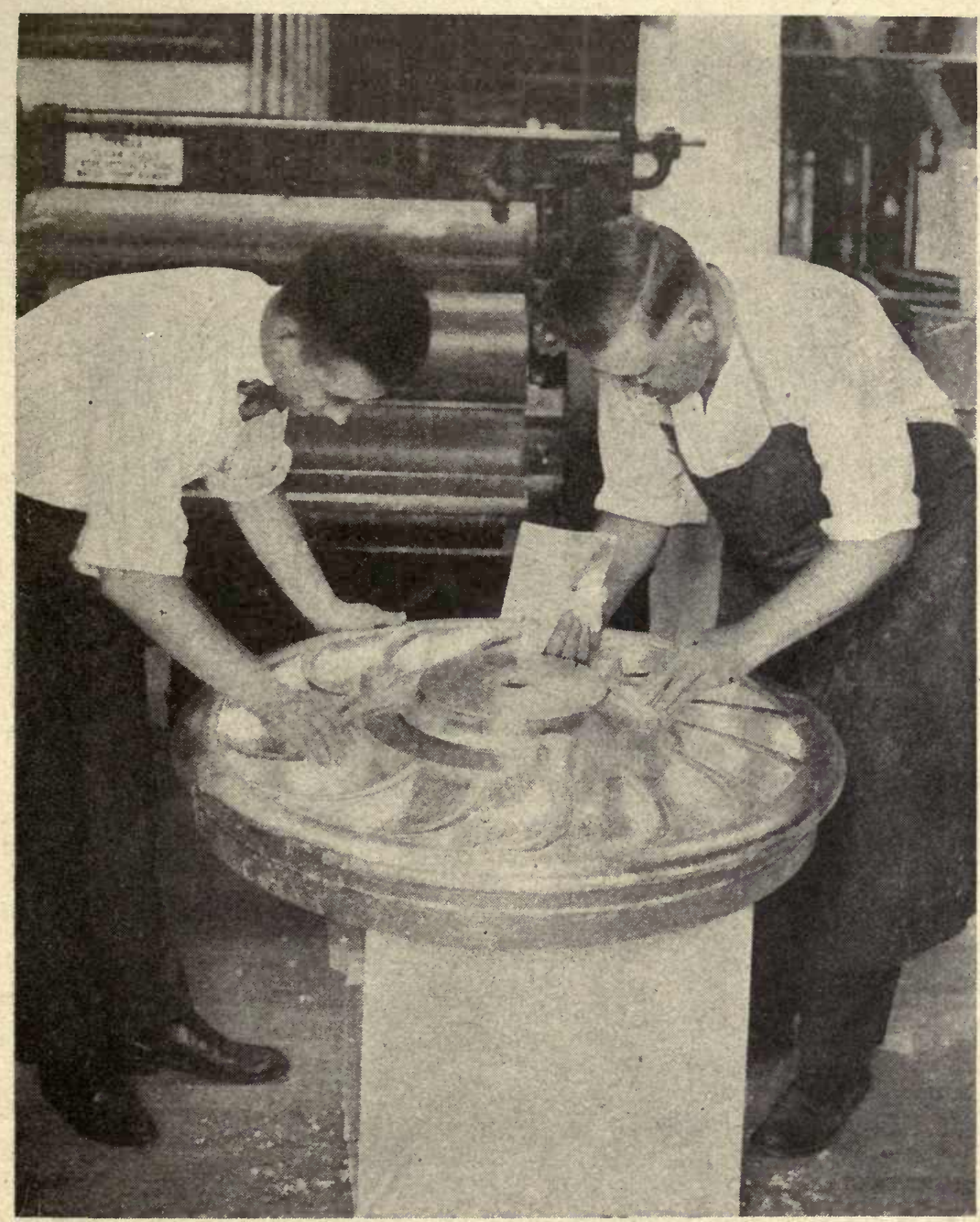

Wooden patterns for castings can be made practically moisture proof by an aluminum leaf coating and so prevented from warping, swelling, or shrinking. Car-wheel patterns protected in this way are now in use by several large foundries. 


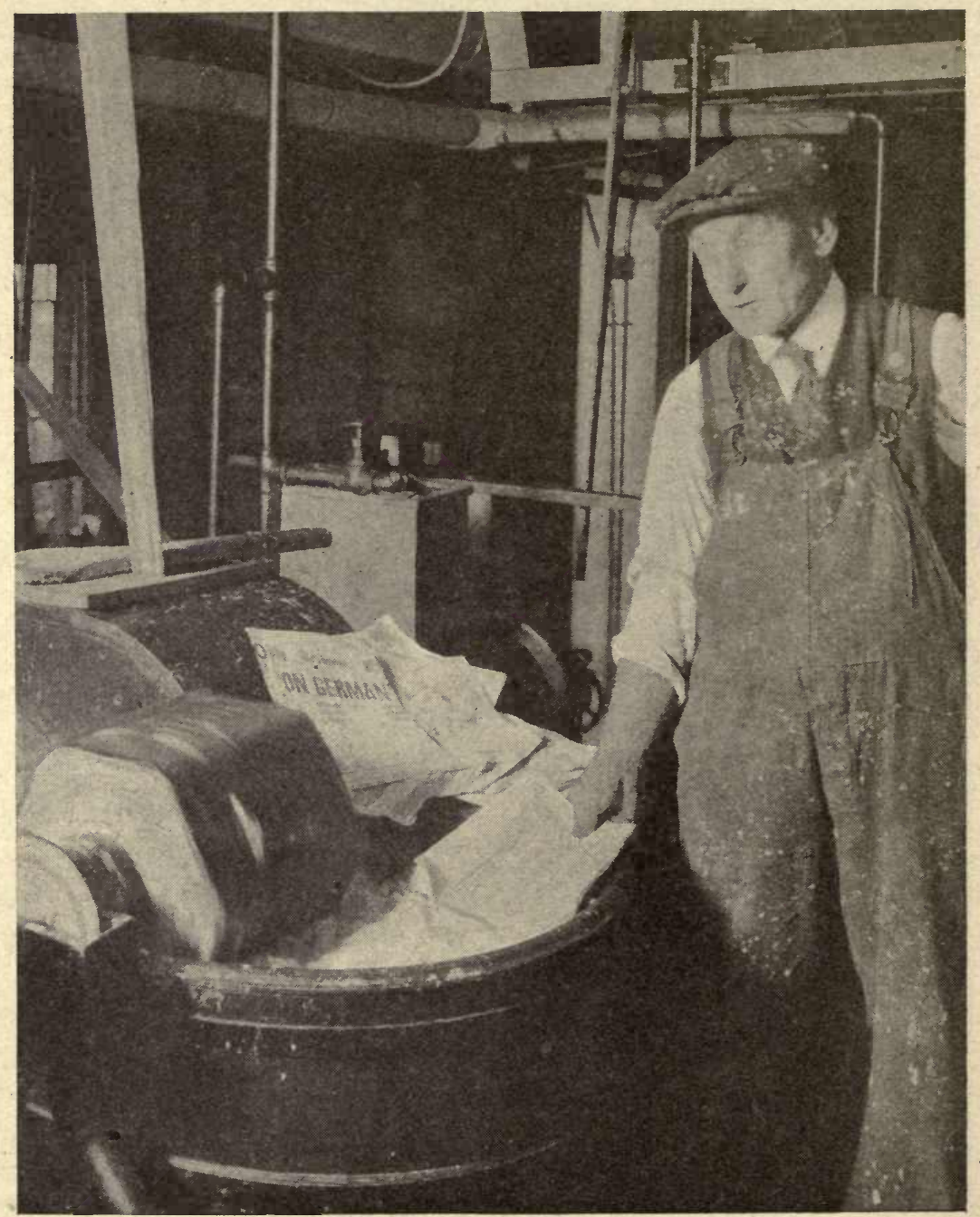

Old newspapers can be de-inked by the use of bentonite, a highly colloidal clay, to which the ink particles adhere after being loosened from the paper in the pulp beater. The pulp is then ready to be used again in the manufacture of news paper. 
soon as funds and equipment become available. The suitability for paper making of hull fiber and second-cut cotton linters, formerly of little value, has been demonstrated and a method of preparation worked out that has proved commercially successful.

\section{PULP DECAY.}

A recently begun investigation of the deterioration of pulp wood and wood pulp through fungous infection, now estimated at $\$ 5,000,000$ a year; is leading to the proper remedies for this great economic loss.

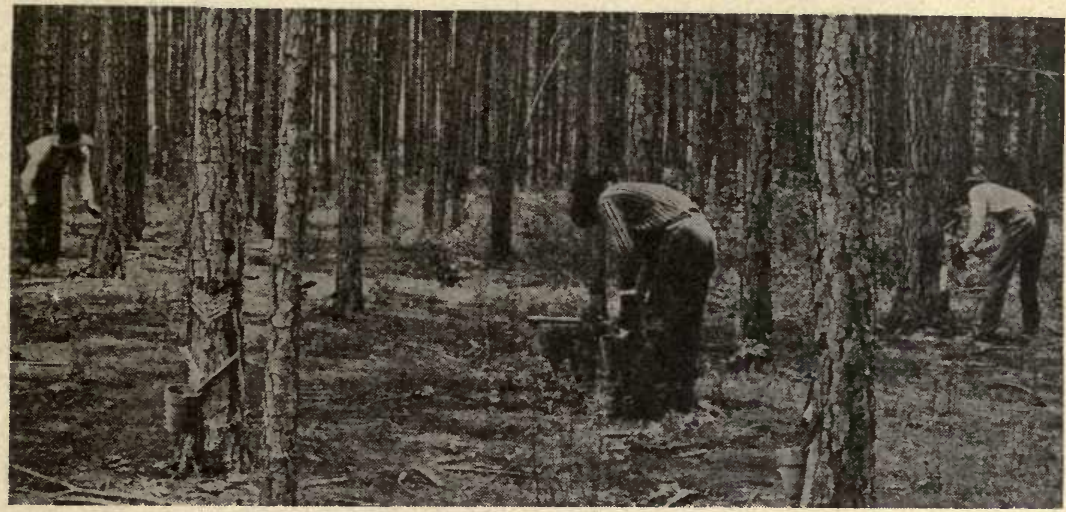

DERIVED PRODUCTS.

HARDWOOD DISTILLATION.

The distillation of hardwoods for the production of wood alcohol, acetate of lime, and charcoal offers one of the best methods for the utilization of hardwood wastes, such as tops, limbs, and slabs. The first work of the Laboratory along this line was a study of the comparative value of different species as distillation woods - at that time only beech, birch, and maple were used commercially. All the important hardwoods have been tested, and several new species, such as oak ànd hickory, are now in use.

Methods have been developed whereby the yield of alcohol and acetate can be considerably increased by a system of temperature control without extending the time of distillation and with a decrease in the amount of fuel required. These methods have been adopted by most of the commercial plants. Encouraging results have been obtained in work now under way on other methods for increasing the yields, such as the treatment of the wood with chemicals previous to distillation.

The production of flotation oils from hardwood tar is a promising method of utilization which has been the subject of much investigation of the Laboratory. Several satisfactory flotation oils have been produced, and the commercial utilization of hardwood tar is increasing. 
TURPENTINE AND ROSIN.

Very valuable results have been obtained by experimental field work in improving methods of obtaining crude turpentine from the tree. A new method has been developed which has increased the yield of turpentine and decreased the bad effect on the tree and reduced the danger from fire. This method has been adopted by almost the entire industry. A complete study has also been made of the amount and composition of the turpentine from several western pines. The changing conditions in this industry due to the rapid depletion of virgin stands of long-leaf pine make it desirable to develop turpentining methods which are especially applicable to second-growth timber and to long-continued operation on the same tree, instead of the usual three to five year operations.

\section{ETHYL (GRAIN) ALCOHOL.}

A promising method of utilizing profitably large quantities of wood waste depends upon the conversion of the cellulose into ethyl alcohol. It has long been known that wood cellulose can be converted into fermentable sugar by suitable treatment with dilute acids at high pressures, but until recently the process has not met with commercial success. Investigation at the Laboratory involved the design and installation of apparatus of semicommercial size and a detailed study of the influence of such variables as pressure, temperature, time concentrations of acid and water, and many others. Partly as a result of these experiments the process is now a commercial success and offers a new means of utilization which will be a source of heat and power of immense economic importance. The two plants now operating in this country have a combined daily capacity of about 9,000 gallons of 95 per cent alcohol. The high quality and purity of the products are attested by the great demand for this - alcohol for the preparation of pharmaceuticals and colognes.

SAWDUST FOR STOCK FOOD.

Another study that has recently been sfarted is the production of a stock food from sawdust. As in the manufacture of ethyl alcohol, the cellulose is first converted into sugar by treatment under pressure with dilute acid, and this sugar, after being extracted and boiled down to a thick molasses, is mixed with the sawdust residue. This so-called "wood meal" has been substituted for one-fourth the ordinary grain ration of the cattle, with a resulting increase in their weight and no decrease in the yield of milk.

- OTHER DERIVED PRODUCTS.

Other products derived from trees or forest materials, and thereiore within the scope of the Laboratory's work, are tannins, gums, balsams, essential oils extracted from the wood, roots, bark, or leaves of varinis 


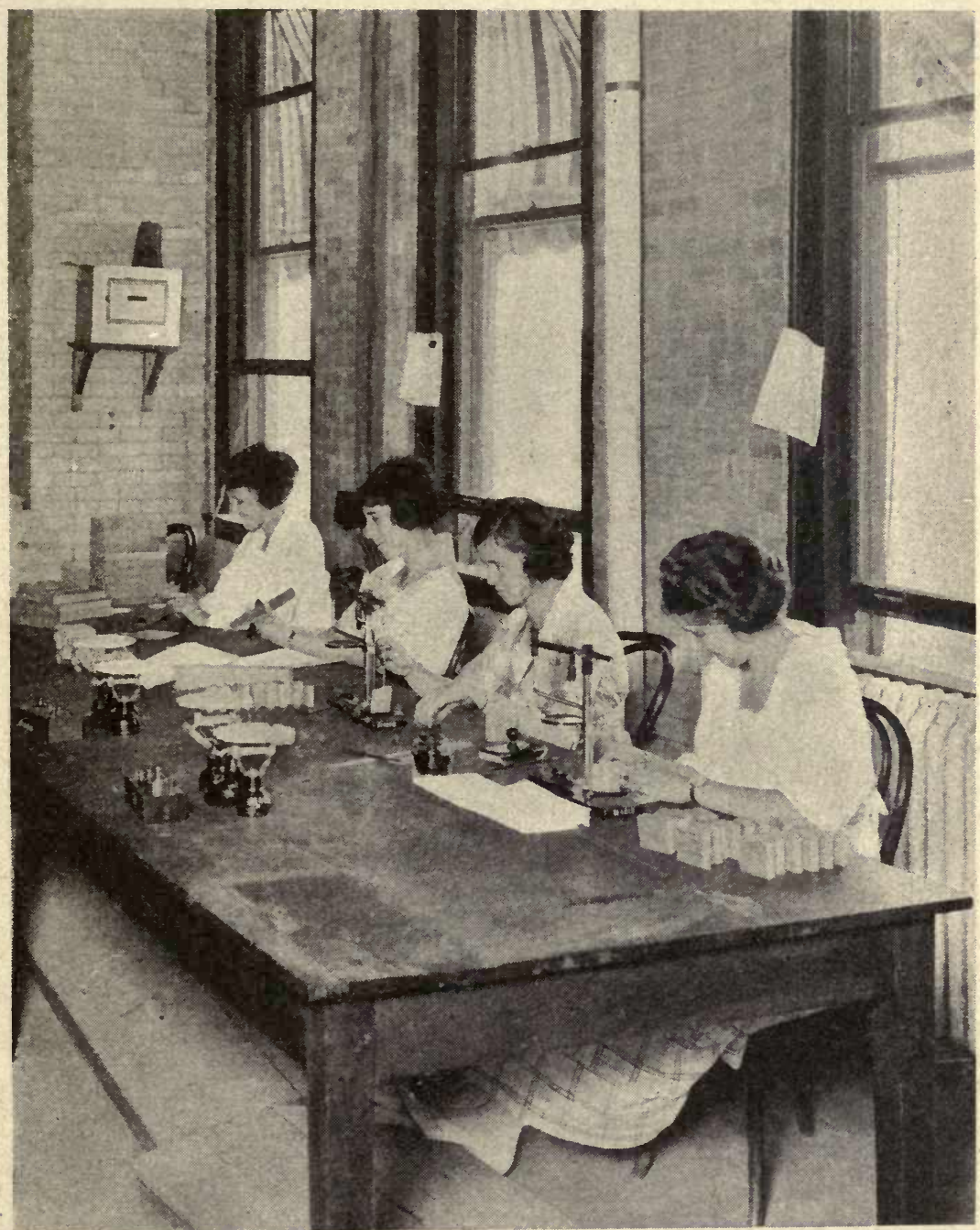

Aside from its value in laboratory tests, the determination of the moisture content of wood is so important in connection with the various uses of wood that every wool working factory should become familiar with the simple process. A knowledge of the moisture content of the stock often makes it possible to avoid costly manufacturing difficilties. 


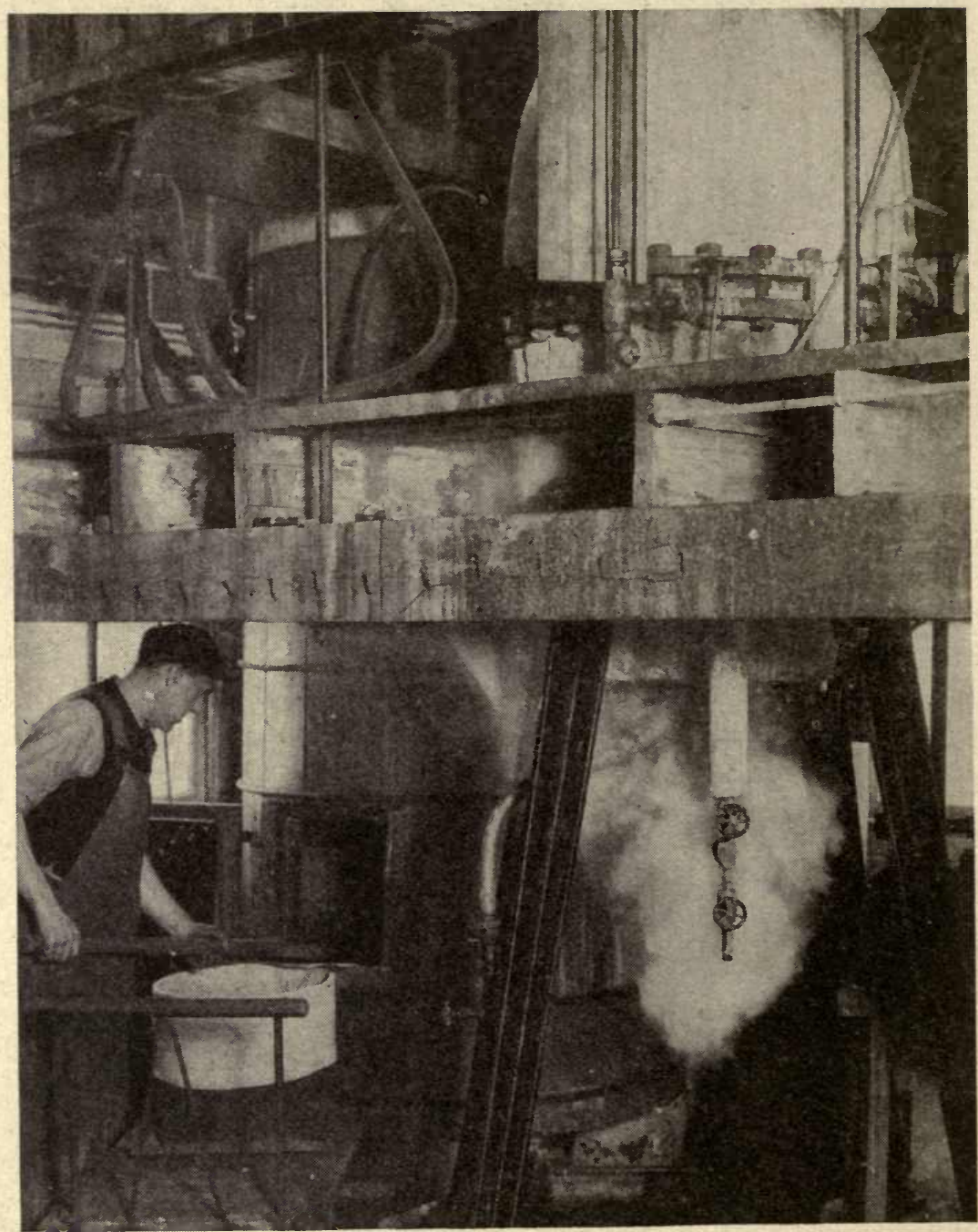

Special small-scale digesters for the manufacture of chemical pulp provide facilities for the study of. pulping problems at a moderate cost, preliminary to a cooperative mill test. 
trees, and producer gas manufactured from wood. The chemical derivatives of cellulose, while not yet touched upon, also offer a fertile field for investigation.

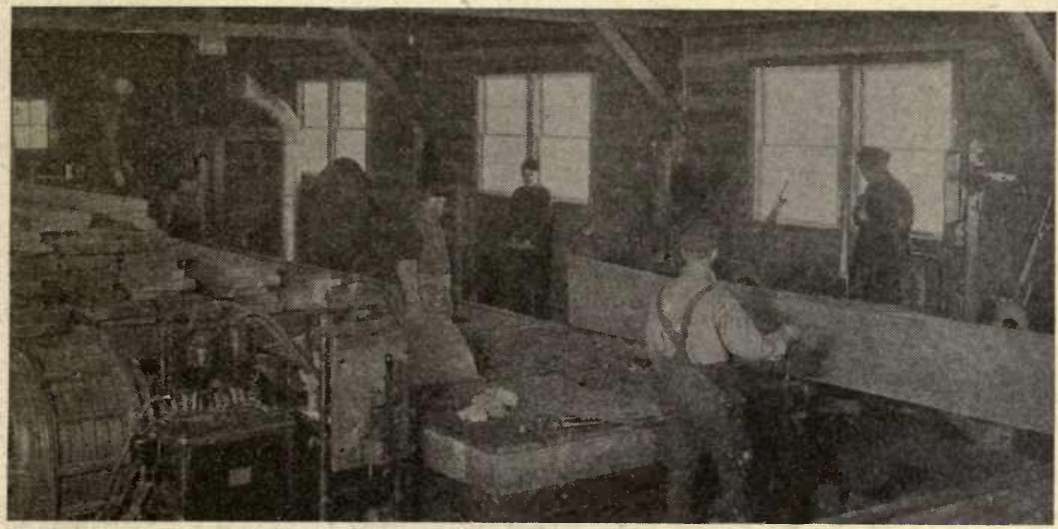

INDUSTRIAL -INVESTIGATIONS.

MECHANICAL UTILIZATION OF WASTE AND LOW-GRADE MATERIAL.

Mechanical as well as chemical processes offer a promising field for the profitable utilization of wood now wasted and for the steadily increasing amount of small and low-grade material coming from secondgrowth stands. Only 30 per cent of the wood in a forest now gets into the form of seasoned, unplaned lumber. Of this, an additional io to 25 per cent is lost in the process of manufacture. In extreme cases as little as 3 per cent of the wood in the forest may reach the finished product.

SURVEY OF WOOD WASTE.

How to reduce to a minimum these losses in logging and manufacture constitutes a research problem of far-reaching scope and significance. The Laboratory has undertaken a comprehensive survey of the present practice and its results in some of the more important wood-using industries. This will be followed by more intensive investigations of equipment, methods, and processes with a view to determining possible modifications and improvements. These investigations will be conducted both in the woods and at the mill and will include studies leading to increased efficiency of operation as well as to closer utilization.

\section{DIMENSION STOCK.}

The manufacture of small-dimension stock offers a striking example of the opportunity for reducing present wastes in manufacture. It has been estimated that all of the five or six billion board feet used each year in the manufacture of articles made from such stock could be secured from material now wasted. Whether or not this is true, there is no question that present wastes could be greatly reduced by standard- 


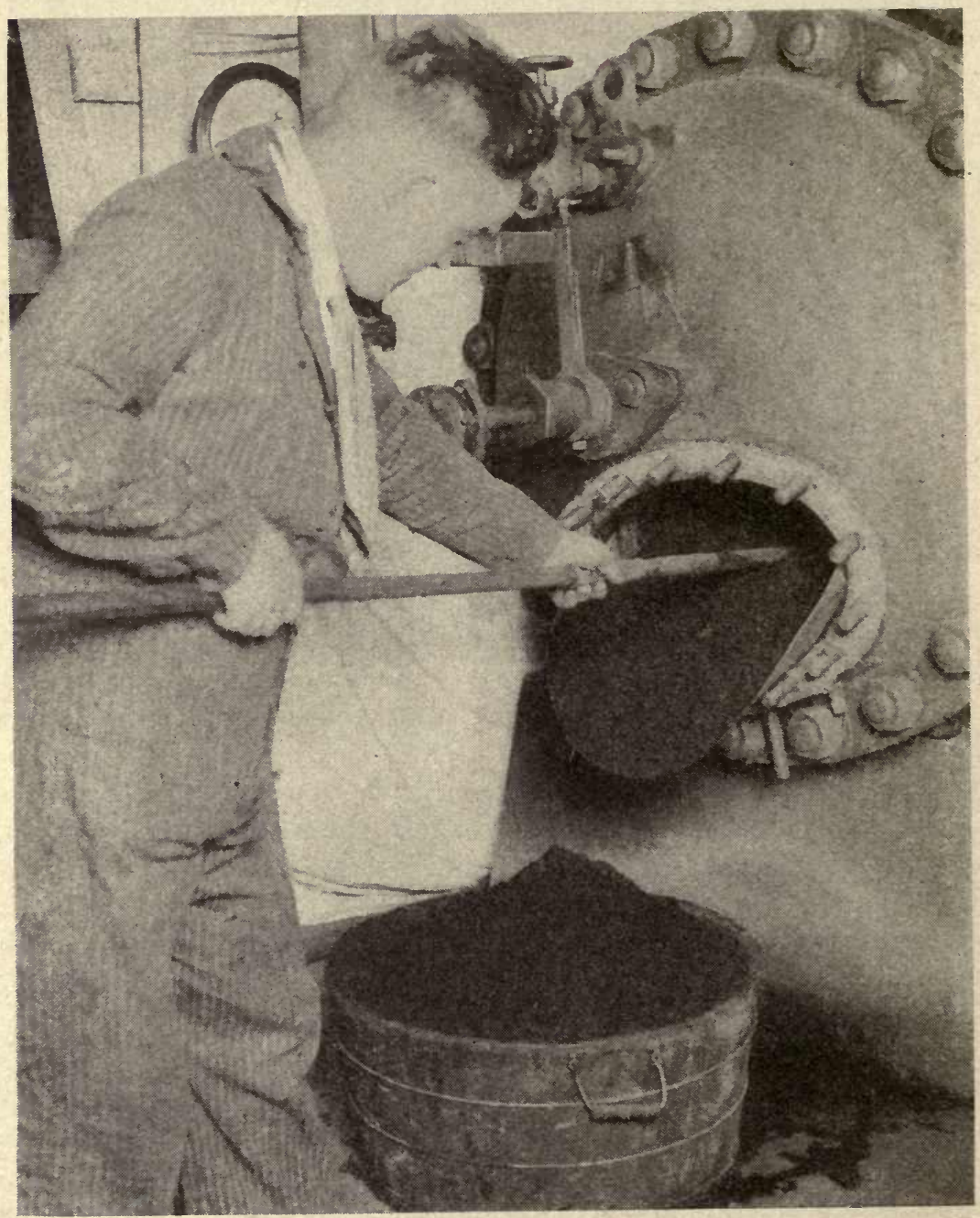

The first step in the manufacture of cattle food from sawdust is to cook the sawdust with dilute acid in a steam-pressure cylinder. This converts a part of the wood into sugars and renders the remainder more digestible. Hydrolized sawdust is being successfully fed to cattle as a considerable part of their concentrate ration. 


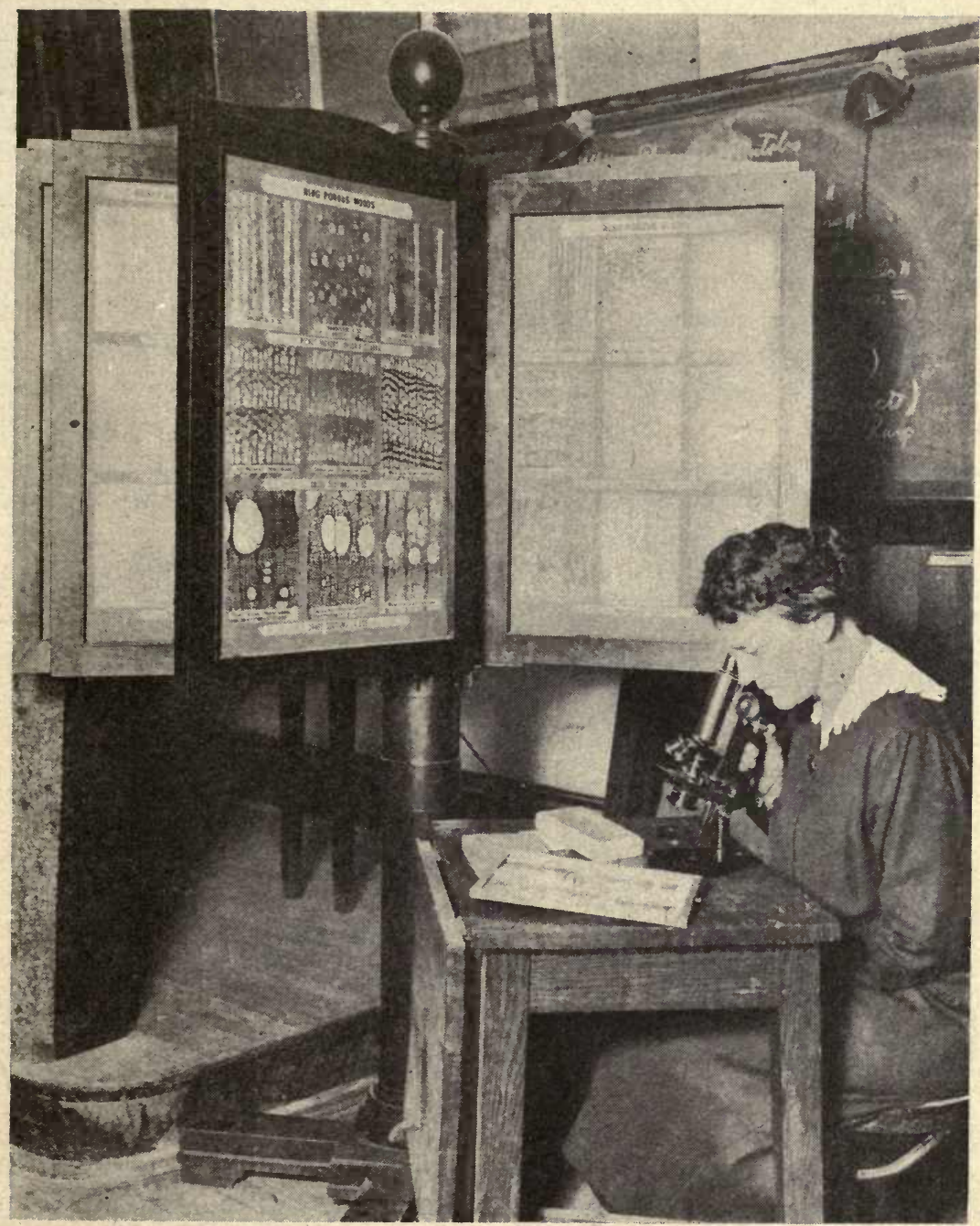

IIth a microscope it is possible to identify wood from practically any of our native trees. The revolving chart shows the diversity in wood structure brought out under a lens. 
izing dimension sizes, by cutting dimension stock directly from the log instead of remanufacturing it from lumber, and by an interchange between industries that would result in the utilization by one industry of what is now regarded as waste in another. Studies along these lines have been undertaken by the Laboratory and will be extended as rapidly as possible.

\section{SECOND-GROWTH STANDS.}

Another problem of first importance has to do with finding a profitable and economical use for the small sizes and low grades on which we shall have increasingly to depend as the virgin forests are replaced by secondgrowth stands. This problem includes also the finding of uses for species now without markets. To a considerable extent the practice of forestry is dependent on developing methods by which the material of all species produced by these stands can be used in place of the high-grade material of a few species from virgin forests to which we have hitherto been accustomed. This involves not only perfecting the technique of built-up and laminated construction, but the introduction of new uses and new methods of manufacture. Investigation of these and related problems will go far toward enabling us to eliminate present wastes and to make the most of our wood supply.

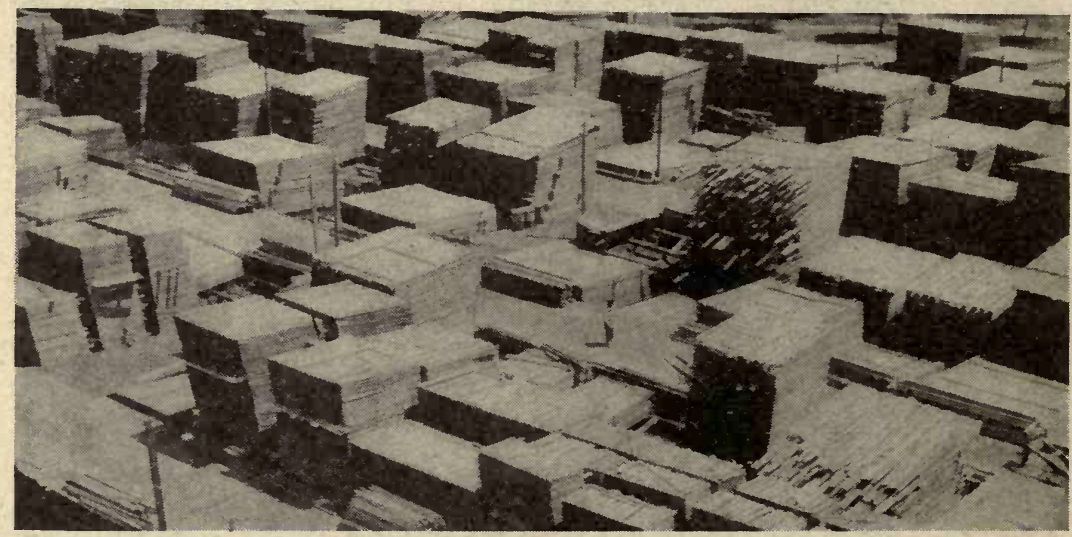

PATHOLOGY.

The work of this section is conducted by the Bureau of Plant Industry of the Department of Agriculture. General studies of the durability and decay of wood are carried on.

DURABILITY OF UNTREATED WOOD.

The relative durability of different woods and the effects of moisture and wood-destroying fungi upon the life of the wood have been studied for many kinds of American woods. Data have been obtained upon the least and most favorable temperatures for the growth of fungi and the amount of heat required to stop their growth. An application of this work is the control of so-called "dry rot" in buildings. 


\section{DECAY IN BUILDING TIMBER.}

Extensive investigations to determine the prevalence of decay in buildings throughout the United States have been made, and from information collected over a ro-year period recommendations have been developed as to-changes in architectural design, proper species for different uses, and suitable antiseptic treatments.

\section{SANITATION OF STORAGE YARDS.}

Unsuspected losses by wood users resulting from improper storage of wood aggregate several million dollars annually. Studies and recommendations have been made on storage of general lumber stocks at sawmills and retail yards, the storage of manufactured wood products, such as vehicle parts, boxwoods, veneers, and staves, and also the storage of pulp wood and pulp. Infection begun in the yard frequently is passed on in the manufactured product to other wood with which the infected material is used:

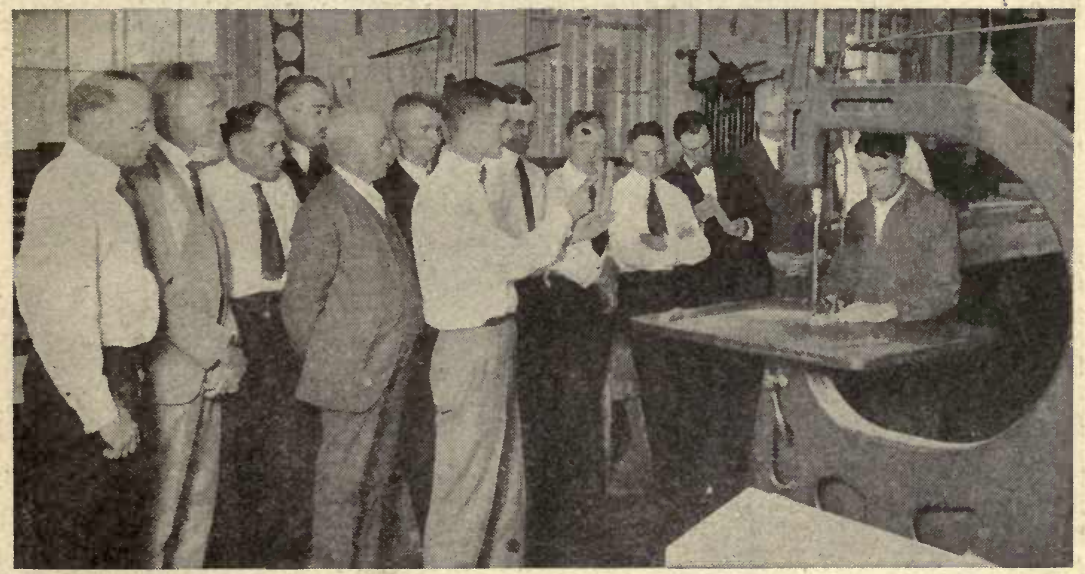

HOW TO USE THE LABORATORY.

INFORMATION FREE.

The Laboratory, being a public institution, makes its information available to the public as rapidly as possible. This it does through personal contact and through reports written during the progress of investigation and upon their completion, so that all information of value is published, either as bulletins or circulars by the Government, in technical notes, by correspondence, or as special articles in trade journals and technical and scientific papers.

Investigations are undertaken both independently and on a cooperative basis, but all investigations must be of a research character that will give information or results of value in attaining the general objects aimed at by the Laboratory. 


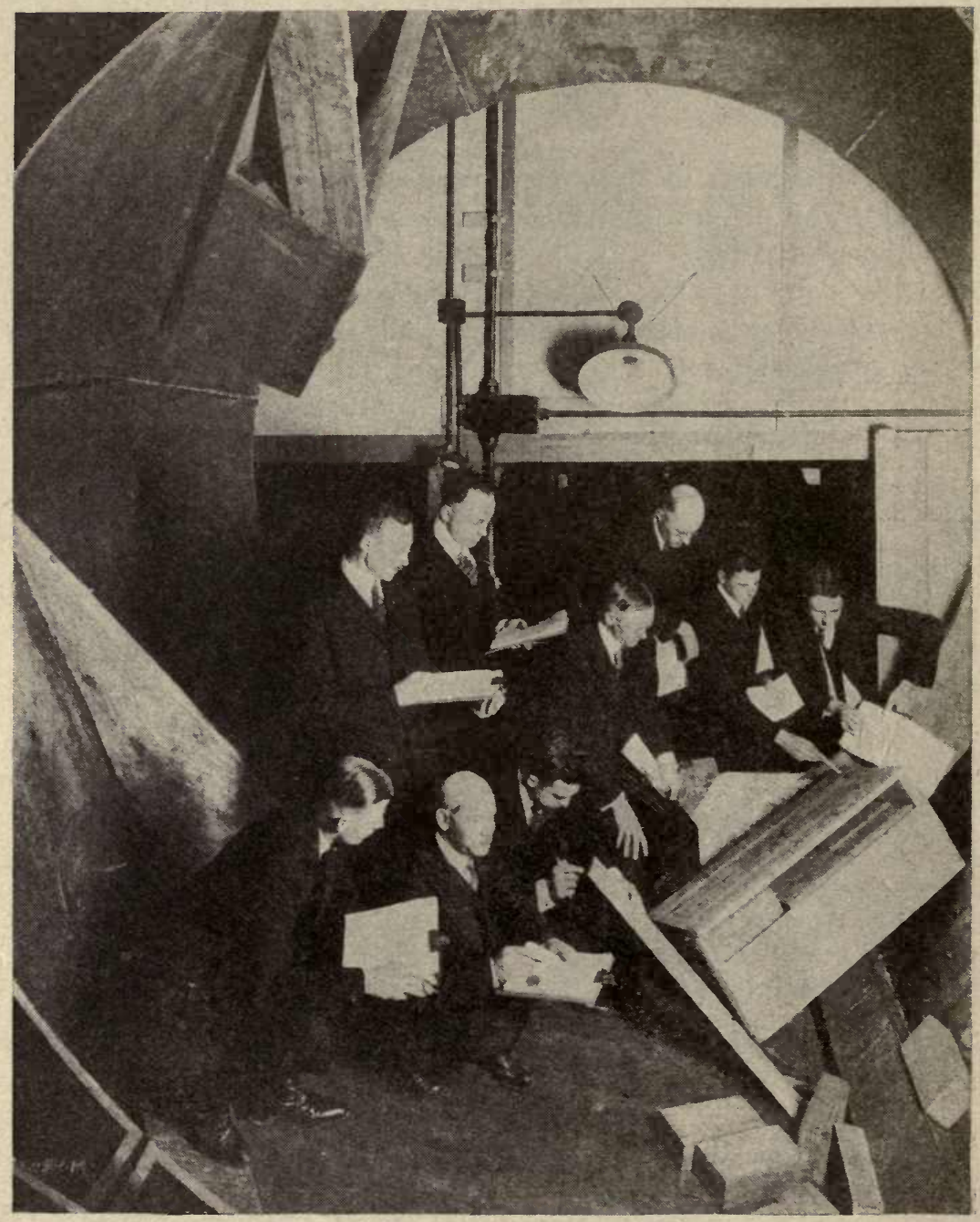

Classes in boxing and crating at the Laboratory make use of the $1_{4}$-foot drum testing machine to investigate the serviceability of shipping boxes. The manufacturers and shippers in the group traveled an average of 2,000 miles each to attend the one-week course 
COOPERATION.

As a general rule, no investigation conducted by the Laboratory is regarded as complete until the results obtained experimentally have been checked on a commercial scale and their industrial application determined. This is ordinarily accomplished through cooperation with individuals or companies that use wood and are commercially interested in developing new or better processes or products.

FORMAI, COOPERATION AT EXPENSE OF COMPANY.

In cases of formal cooperation, there should be a remuneration to the Laboratory depending on the cost of the work done for the cooperator, including the time and expense of the members of the Laboratory detailed to the project, and its general supervision. When practically all of the work proposed is investigative and the results of value chiefly to the general public, the charge to the cooperator may be comparatively low or eliminated altogether.

\section{CONSULTATION ON SPECIAL PROBLEMS.}

Anyone is at liberty to correspond with the Laboratory about particular problems dealing with the utilization of wood and will receive answers based on whatever information is available on the subject. The staff of the Laboratory is also available for consultation work, provided the solution of the problem under consideration will further its general research work, or has direct bearing upon it.

Personal visits to the Laboratory for consultation have proved very satisfactory.

The Laboratory may, on request, examine the methods of individuals or companies used in handling forest products and prepare plans for improving such methods, provided that the purpose is primarily to reduce waste and to obtain information of general value to the industries concerned.

\section{COURSES OF INSTRUCTION.}

Two short cooperative courses of instruction are given monthly at the Laboratory - one in kiln-drying, the other in boxing and crating. These courses are of particular value to superintendents, lumber and production men, and foremen in wood-using plants. The instruction is under the supervision of a staff of competent specialists and the enrollment is limited to 16 men in each course, so that proper attention may be given to individual problems. Priority of application governs admission to the courses, and the classes are usually filled for two or three months ahead.

Detailed information concerning any of the work of the Laboratory will be gladly furnished. Inquiries should be addressed to the Director, Forest Products Laboratory, Madison, Wis. 




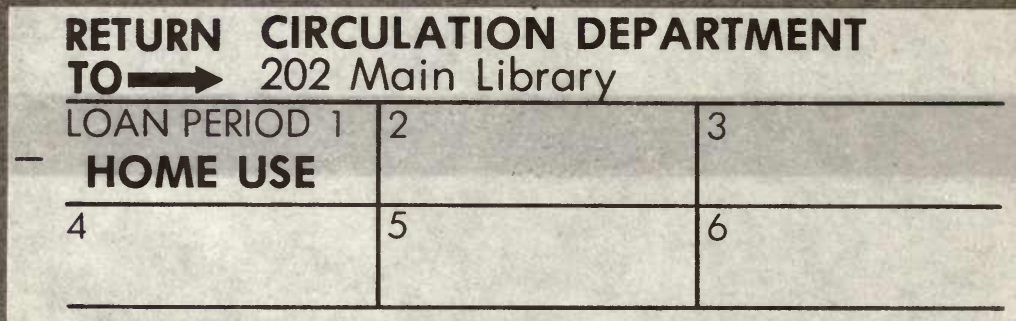

ALL BOOKS MAY BE RECALLED AFTER 7 DAYS

Renewals and Recharges may be made 4 days prior to the due date. Books may be Renewed by calling $\mathbf{6 4 2 . 3 4 0 5}$

\section{DUE AS STAMPED BELOW}

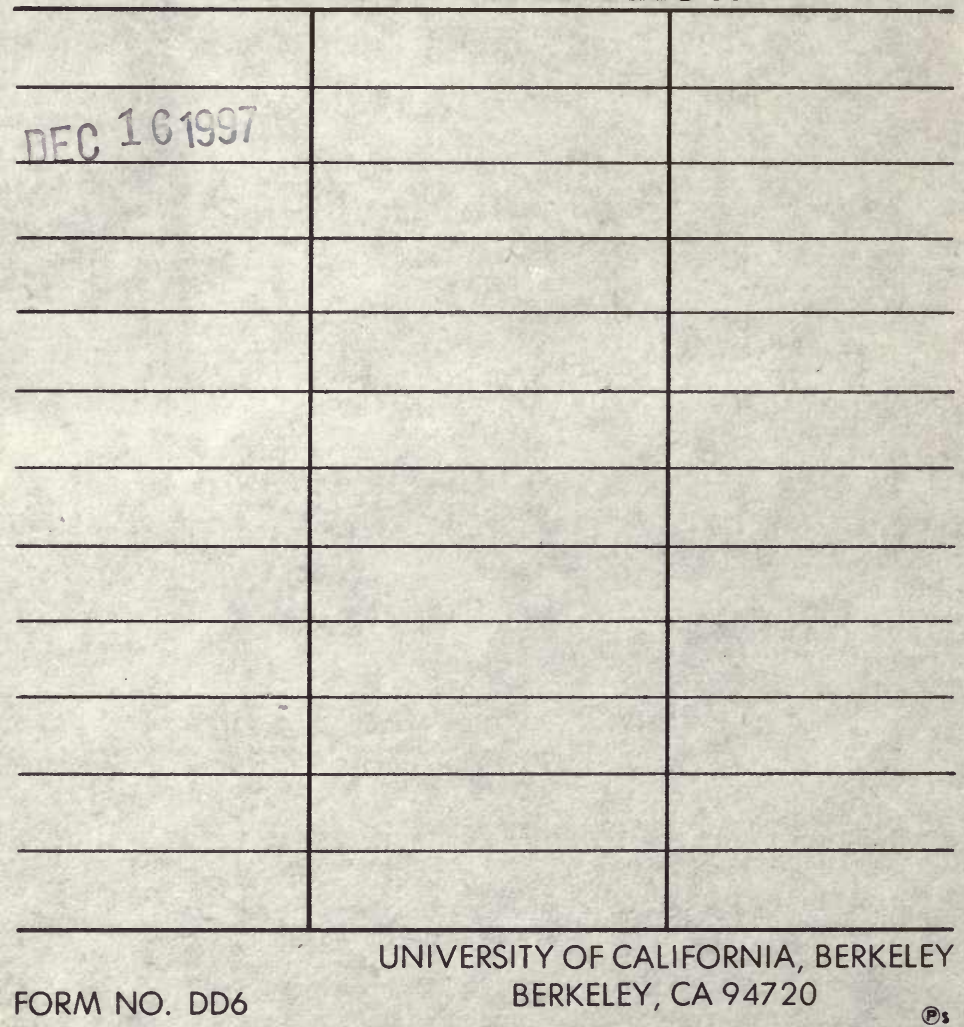


с0326b 438

$50056 ?$

UNIVERSITY OF CALIFORNIA LIBRARY

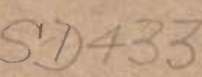

2

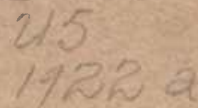


3.

tertatinas

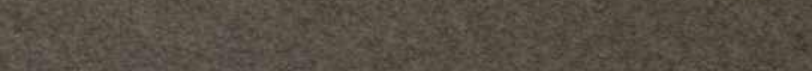

C Wh

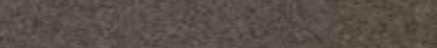

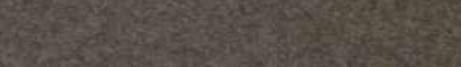

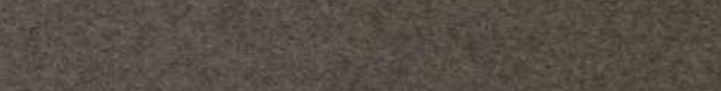

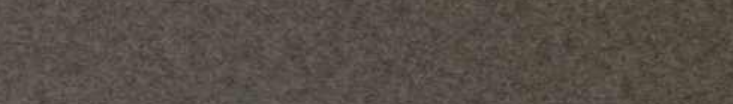

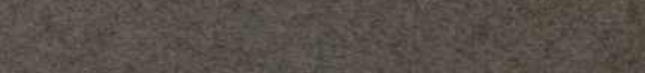

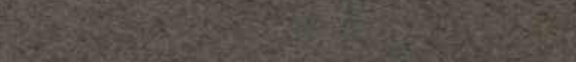

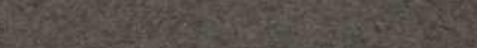

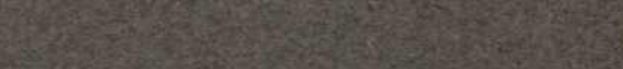

cosing

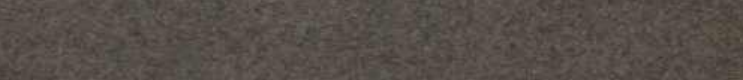

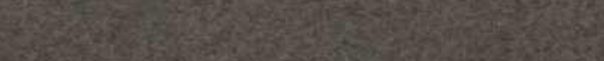

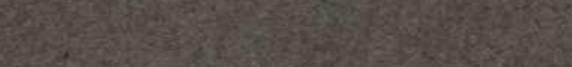

की

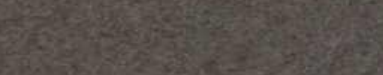

3.

P. S.

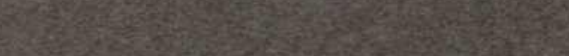

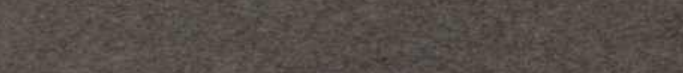

1.

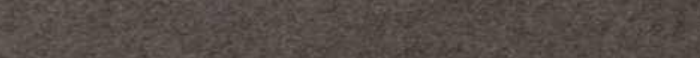

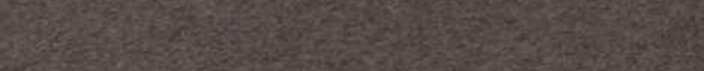

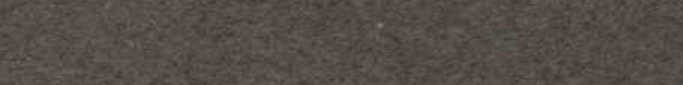

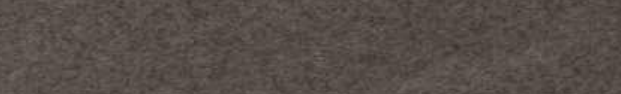

3.

Q68.

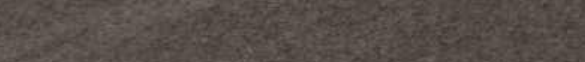

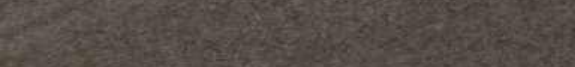

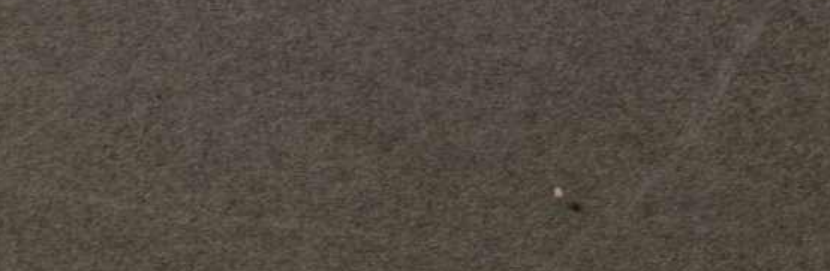

